Microbes and Health, June 2012, 1(1): 19-22

\title{
Lethal Effects of Salmonella Toxin Isolated from Layer Chickens
}

\author{
Farzana Afroz, Md. Mostafizer Rahman, Md. Fakhruzzaman* and Mezbah Uddin ${ }^{1}$
}

Department of Microbiology, Hajee Mohammed Danesh Science and Technology University, Dinajpur-5200, Bangladesh. ${ }^{1}$ Department of Microbiology and Hygiene, Sylhet Agricultural University, Sylhet, Bangladesh.

*Corresponding author's e-mail: fakhrul.hstu@gmail.com

[Received: 01 May 2012, Revised: 20 May 2012, Accepted: 20 June 2012]

\begin{abstract}
A B S T R A C T
This study was conducted to determine lethal effects of Salmonella toxin isolated from layer chickens. The chickens were collected from Paragon Poultry Farm, Rangpur and Ahana Poultry Farm, Dinajpur and brought to the Microbiology Laboratory at the Hajee Mohammad Danesh Science and Technology University, Dinajpur, to isolate and identify Salmonella spp., and subsequent toxin separation from the isolated organisms for the detection of lethal effects of the toxin. The lethality of isolated toxin was evaluated in day-old-chick. The toxicity in case of oral administration was $50 \%$, whereas the rate was $80 \%$ when chicks were administered through intra-peritoneal route. The chick mortality rate was $65 \%$. For toxin extraction, Salmonellae were isolated and identified from layer chickens. Out of 196 organ samples, 51 were found to be positive for Salmonella spp., of which 33 and 18 were of Paragon Poultry Farm and Ahana Poultry Farm, respectively. Total 60 chickens (27 pullets and 33 layers) were screened. The percentages of positive samples (liver, spleen, lung, heart) from these farms were 29.82 and $20.73 \%$, respectively and the average prevalence of Salmonellae was 26.02\%. In case of Paragon Poultry Farm, the prevalence of salmonellosis in pullet was $23.08 \%$ and in layer, it was $35.48 \%$, whereas in case of Ahana Poultry Farm, the prevalence was 16.67 and $23.91 \%$, respectively.
\end{abstract}

Keywords: Salmonella toxin, Lethal effect, Layer chickens

(C) 2012 Microbes and Health. All rights reserved

\section{Introduction}

Poultry rearing is now a rising sector in Bangladesh, because of its perceived assured and quick good return could be achieved in relatively short period of time by a moderate amount of investment. Salmonellosis is a silent killer of poultry causing constant economic losses to this sector or industry and therefore, is an obstacle in establishing this industry (Khan et al., 1998). Salmonellosis is one of the most significant disease of chicken because the causal agent is vertically transmitted from parent to offspring. Fowl typhoid and Pullorum diseases are septicemic diseases primarily of chickens and turkeys. The diseases are caused by Gram-negative bacteria, Salmonella gallinarum and Salmonella pullorum, respectively. Pullorum disease formerly referred to as fatal septicemia of chicks, white diarrhea or white bacillary diarrhea.

Fowl typhoid is frequently referred to as a disease of adult birds; there are also reports of high mortality in young chicks (Christensen et al., 1992). With the great expansion of poultry rearing and farming Fowl typhoid caused by $S$. gallinarum is the most devastating disease in Bangladesh (Begum et al., 1993). The epidemiology of Fowl typhoid

To cite this article: Afroz F, MM Rahman, M Fakhruzzaman and M Uddin, 2012. Lethal Effects of Salmonella Toxin Isolated from Layer Chickens, Microbes Health, 1(1): 19-22. and Pullorum disease in poultry, particularly with regard to transmission from one generation to the next is known to be associated with infected eggs. The birds that survive from clinical disease when infected at young stage show some signs of infection but can remain carriers. Although more than 2,300 serotypes of Salmonellae have been identified, only $10 \%$ have been isolated from poultry (Gast, 1998). Chickens are the natural hosts for the $S$. gallinarum and S. pullorum (Pomeroy and Nagaraja, 1991).

The disease can be controlled by maintaining high level of biosecurity, routine serological tests, screening of birds positive to Salmonellae, and vaccination. However, effective vaccine made from local isolate is not adequately available in the market for preventive measure in Bangladesh although a bivalent salmonella vaccine is being produced at the Department of Microbiology and Hygiene, Bangladesh Agricultural University, Mymensingh, which is marketed by Phenix Hatchery Ltd., Gazipur, Bangladesh. Besides, toxoid vaccine could be a good choice produced from toxin extracted from Salmonellae field isolates. The present study was undertaken to detect the lethal effects of toxin extracted from Salmonellae field isolates that could be a candidate in future to use as toxoid vaccine.

\section{Materials and Methods}

Study area and duration

The study was conducted during the period from March, 2011 to Aug, 2011 at Paragon Poultry Farm (layer), Rang- 
pur and at Ahana Poultry Farm (layer), Dinajpur. The samples were collected from birds of selected layer farms and brought to the Microbiology Laboratory of the Department of Microbiology, Hajee Mohammad Danesh Science and Technology University (HSTU), Dinajpur, for laboratory analysis.

\section{Isolation and identification of Salmonellae from chicken}

\section{Cultural characterization}

A total of 196 field samples comprising liver, spleen, heart and lung of 60 dead chickens of study areas were aseptically collected and brought to the Microbiology Laboratory of the Department of Microbiology, HSTU. Isolation and identification of Salmonellae were performed as per procedures described by OIE (2000), Merchant and Packer (1967) and Cowan (1985). Primary culture was performed in Nutrient agar and Nutrient broth media. Sub-culturing was performed in eosin methylene blue (EMB) agar, MacConkey (MC) agar, salmonella-shigella (SS) agar and brilliant green $(\mathrm{BG})$ agar to obtain pure culture and to study the cultural characteristics.

\section{Morphological characterization}

The representative Salmonellae isolates from SS agar were stained by Gram staining (Merchant and Packer, 1967). Motility test was performed by Hanging drop preparation.

\section{Biochemical characterization}

Isolated organisms with supporting growth characteristics of Salmonellae on various culture media were maintained on SS agar and BG agar and were subjected to biochemical tests viz. sugar fermentation test, triple sugar iron (TSI) agar slant reaction, methyl red-Voges Proskauer (MR-VP) test, indole reaction, and motility indole urease (MIU) test as described by Merchant and Packer (1967).

\section{Toxin extraction from Salmonellae field isolates}

The isolated Salmonellae were inoculated in Nutrient broth culture media and kept overnight at $37^{\circ} \mathrm{C}$ for 24 hours in bacteriological incubator. Growth of Salmonellae in broth culture was mixed with an equal volume of phosphate buffer saline (PBS) in test tubes. The test tubes were placed in a rotary shaker at room temperature for 8 hours and centrifuged at 3,000 rpm for 30 minutes. The supernatant fluids were then passed through $0.45 \mu \mathrm{m}$ mill- ipore filter for the separation of toxin from the bacteria. The filtrates were then mixed with saturated solution of ammonium sulphate at room temperature and centrifuged at 3,000 rpm for 30 minutes. The supernatant was decanted and the precipitated mass of toxins were then resuspended with $5 \mathrm{ml}$ PBS (pH 7.2). Then, pure toxins were collected in a sterile test tube and injected through intraperitoneal route or given orally to day-old-chick. The dead chicks were subjected to postmortem examinations to detect the lethal effect.

\section{Detection of lethal effect of Salmonellae toxin}

Lethal effect of Salmonella toxin was detected in day-old chick. Thirty chickens were taken on random basis, out of them one group of ten 1-day-old SPF chicks were orally inoculated with $200 \mu \mathrm{l}$ Salmonella toxin extracted from field isolate. Another group of $10 \mathrm{SPF}$ chicks were inoculated through intra-peritoneal route with $2 \mathrm{ml}$ Salmonella toxin extracted from field isolate, and 10 SPF chickens were kept as control. In case of oral administration, the dose of toxin was $200 \mu \mathrm{l}$ but it was only $2 \mathrm{ml}$ in case of intra-peritoneal administration due to variation in route. After 1 or 2 days, chicks that died were subjected to postmortem examination and organs (liver, spleen and cecal tonsils) were collected to see the postmortem changes.

\section{Results}

Prevalence of Salmonella spp. isolated from internal organs of dead chickens

Salmonellae were isolated from 31 samples of liver, 13 samples of spleen, 4 of lung samples and 3 of heart samples and the revealed prevalence of Salmonellae was 38.75, $23.21,10.53$ and $13.64 \%$, respectively (Table 1). The overall cultural prevalence of Salmonellae isolates in dead birds was $26.02 \%$. Among the 80 liver samples, Salmonellae could be isolated from $31(38.75 \%)$ samples.

Table 1. Cultural prevalence of Salmonella spp. isolated from internal organs

\begin{tabular}{lccc}
\hline Sample & Sample (n) & Positive (n) & Prevalence (\%) \\
\hline Liver & 80 & 31 & 38.75 \\
Spleen & 56 & 13 & 23.21 \\
Heart & 22 & 3 & 13.64 \\
Lung & 38 & 4 & 10.53 \\
\hline Total & 196 & 51 & 26.02 \\
\hline
\end{tabular}

Table 2. Prevalence of Salmonellae isolates

\begin{tabular}{lcccc}
\hline Study area & Study population & Prevalence (\%) & Average (\%) & Average (\%) \\
\cline { 2 - 3 } \multirow{2}{*}{ Paragon Poultry Farm } & Pullet & 23.08 & 29.82 & \\
\cline { 2 - 3 } \multirow{2}{*}{ Ahana Poultry Farm } & Layer & 35.48 & \multirow{2}{*}{20.73} & \multirow{2}{*}{26.02} \\
\cline { 2 - 3 } & Pullet & Layer & 23.67 & \\
\hline
\end{tabular}

Table 3. Lethal effect of toxin extracted from Salmonellae isolates

\begin{tabular}{llcccc}
\hline $\begin{array}{l}\text { Route of } \\
\text { inoculation }\end{array}$ & Postmortem findings & $\begin{array}{c}\text { Day-old- } \\
\text { chick (n) }\end{array}$ & $\begin{array}{c}\text { No. of dead } \\
\text { chicks (\%) }\end{array}$ & $\begin{array}{c}\text { No of live } \\
\text { chicks (\%) }\end{array}$ & $\begin{array}{c}\text { Average toxicity } \\
\text { in percentage }\end{array}$ \\
\hline \multirow{2}{*}{ Oral } & $\begin{array}{l}\text { Yellowish liver, Edema in } \\
\text { mesentery, Excessive mucous }\end{array}$ & & & \\
& $\begin{array}{l}\text { in the esophagus, beak, trachea, } \\
\text { clay-like cecal contents }\end{array}$ & 10 & $5(50)$ & $5(50)$ & \multirow{2}{*}{65} \\
\cline { 1 - 2 } Intra-peritoneal & Same & 10 & $8(80)$ & $2(20)$ \\
\hline Control & Not applicable & 10 & & \\
\hline
\end{tabular}


Among the 56 samples tested from spleen, Salmonellae could be isolated from $13(23.21 \%)$ samples. Lungs and heart were also affected to some extent. In this study, simultaneously several different selective media were used to culture the organisms because all of them were not equally suitable for all the serovars of Salmonellae. In addition, specific enriched media and biochemical tests were used for the isolation and identification of Salmonellae.

In Gram staining, the morphology of the isolated Salmonellae from chicken revealed that they were Gram-negative, small rod shaped, single or paired in arrangement under microscope. In motility test, the isolates did not show swinging movement which differentiates the motile bacteria from non-motile and also from $E$. coli, so the isolated Salmonellae organisms were non-motile. The isolated Salmonellae were either $S$. gallinarum or S. pullorum because the isolates were non-motile in MIU test.

\section{Prevalence of isolates}

The percentages of positive samples (liver, spleen, lung, and heart) from Paragon Poultry Farm and Ahana Poultry Farm were 29.82 and $20.73 \%$, respectively and the average prevalence of Salmonellae in the study area was $26.02 \%$. In case of Paragon Poultry Farm, the prevalence of salmonellosis in pullet was $23.08 \%$ and in layer birds $35.48 \%$, and in case of Ahana Poultry Farm, the prevalence in pullet and layer birds was 16.67 and $23.91 \%$, respectively (Table 2).

\section{Lethal effect of toxin of the Salmonellae isolates}

Toxicity to day-old-chicks those were given toxin orally was $50 \%$ and in case of chicks those were inoculated through intra-peritoneal route was $80 \%$. Considering both routes, out of 20 day-old-chick, 13 were died within 1-2 days; average toxicity was $65 \%$ (Table 3 ). In postmortem examination, yellowish liver, edema in mesentery, excessive mucous in the esophagus, beak, trachea, clay-like cecal contents were found.

\section{Discussion}

The study was aimed at determination of lethal effects of Salmonella toxin isolated from layer chickens. The lethal effect of toxin extracted from Salmonellae field isolates was detected in day-old-chick. Percentage of toxicity in case of day-old-chicks those were given toxin orally was $50 \%$ and in case of chicks those were inoculated through intra-peritoneal route, the toxicity was $80 \%$ suggesting that toxins were more efficient when administered through intra-peritoneal route compared to oral route. This could be due to the extreme gastric $\mathrm{pH}$ (acidic environment) that somehow has certain degree of detrimental effect on the toxin. On the other hand, this might be due to use of higher dose in the intra-peritoneal route compared to oral route. Out of 20 day-old-chick, 13 were died showing the toxicity of $65 \%$. In case of organs specificity, Salmonellae were detected from 31 liver samples, 13 spleen samples, 4 lung samples and 3 heart samples. The prevalence was $38.75,23.21,10.53$ and $13.64 \%$, respectively. Among the 80 samples tested from liver, Salmonellae could be isolated from $31(38.75 \%)$ samples which were in close aggrement with the findings of Tibaijula et al. 2003; however, the findings were higher than those of Habib-ur-Rehman (2004). Among the 56 samples tested from spleen, Salmonellae could be isolated from $13(23.21 \%)$ samples which were higher than the findings of Habib-ur-Rehman et al. (2004). In the present study, the overall cultural prevalence of Salmonellae isolates in dead birds was $26.02 \%$, which was lower than the observation of Habibur-Rehman et al. (2004). It might be due to difference in number of birds tested or due to various areas. Habib-urRehman et al. (2004) described $34.50 \%$ cultural prevalence of Salmonellae infection in dead birds where $10.50 \%$ in liver and $10.50 \%$ in spleen while described $47.60 \%$ in liver. From the present research, it was revealed that the liver was the main source for Salmonellae organisms other than the spleen, heart and lung, which is in close agreement with the findings of Sujatha et al. (2003). In this study the isolates from chicken fermented dextrose, glucose, maltose and mannitol and produced acid and gas but did not ferment sucrose and lactose which satisfy the statement of Buxton and Fraser (1977). It was created difficulties when organisms produced only acid in dextrose, glucose, maltose and mannitol because $S$. pullorum sometimes did not produce gas, as produced by $S$. gallinarum.

Alam et al. (2003) observed $23.80 \%$ prevalence of Salmonellae infection in the poultry farms of Dinajpur region. Also, it was indicated that various factors influenced the potential mass morbidity of chickens, for example, possibility to the development and course of an epidemic outbreak of avian Salmonellosis, the spectrum of the causal agents and its dependence on the various environmental conditions. Although the primary habitat of Salmonellae is the intestinal tract, the bacteria may be found in other parts of the body from time to time (Calnek, 1997). Here, the isolation of Salmonella spp. has been recorded from liver, spleen, heart and lung of dead birds repeatedly, but their incidence in different categories of birds has been shown to vary. Many researchers also found these organisms in spleen, liver, lymph nodes as well as in feces (Calnek, 1997).

\section{Conclusion}

In the present study, Salmonella species were successfully isolated from layer chickens. In addition, the toxin was extracted and the lethal effects of the toxin was studied using oral and intra-peritoneal route in day-old-chicks. The average prevalence of Salmonellae in the study area was $26.02 \%$. The extracted toxin was found to be lethal for day-old-chick and the average $65 \%$ toxicity was found irrespective of route of administration. However, the toxicity was higher when the toxin was administered through intra-peritoneal route than that of oral route. Among the internal organs, Salmonellae were found to be more prevalent in liver followed by spleen, heart and lungs.

\section{References}

Alam J, I Koike, M Giasuddin and M Rahman, 2003. Seroprevalence of poultry diseases in native chickens in Bangladesh. 9 $^{\text {th }}$ BSVER Annual Scientific Conference, BSVER Publication No. 24, pp: 26.

Begum F, MSR Khan, KA Chowdhury, MM Rahman and MM Amin, 1993. Studies on immune response of chickens to fowl typhoid vaccine. Bangl J Microbiol, 10: $51-56$

Buxton A and G Fraser, 1977. Animal Microbiology. Vol. 1. Blackwell Scientific Publications, Oxford, London, Edinburgh, Melbourne, pp: 103-115. 
Calnek BW, 1997. Salmonella infection. In: Diseases of poultry: $10^{\text {th }}$ Ed. Iowa State University Press, Ames, Iowa, USA, pp: 81-129.

Christensen JP, JE Olsen, HC Hansen and M Bisgaard, 1992. Characterization of Salmonella enterica serovar Gallinarum biovars gallinarum and by plasmid profiling and biochemical analysis. Avian Pathol, 21: 461-470.

Cowan ST, 1985. Cowan and steel's manual for identification of medical bacteria, $2^{\text {nd }}$ Ed. Cambridge University Press, Cambridge, London, pp: 138-139.

Gast RYL, 1998. Paratyphoid infections. In : (B. W. Calned, H. J. Barmes. C. W. Beard, L. R. McDougld and Y. M. Saif, eds). Diseases of Poultry: $10^{\text {th }}$ Ed. Ames, IA: Iowa State University Press, pp: 97-121.

Habib-ur-Rehman S, 2004. Incidence and Gross pathology of Salmonella gallinarum infection in chicken. J Anim Vet Adv, 3: 175-178.

Khan MAHNA, ASM Bari, MR Islam, PM Das and MY
Ali, 1998. Pullorum disease in semi-nature chicks and its experimental Pathology. Bangl Vet J, 32:124-128

Merchant IA and RA Packer, 1967. Veterinary Bacteriology and Virology. $7^{\text {th }}$ Ed. The Iowa State University Press, Ames, lowa, USA.

Office International des Epizooties (OIE), 2000. Manual of standards for diagnostics tests and vaccines.

Pomeroy BS and KV Nagaraja, 1991. Fowl Typhoid. In: Diseases of Poultrv', 9'th Ed. BW Calnek, HJ Barnes, CW Beard, WM Reid, and HW Yoder, Jr. Eds. Iowa State University Press, Ames, Iowa, pp: 87-99.

Sujatha K, K Dhanalakshmi and AS Rao, 2003. Isolation and characterization of Salmonella gallinarum from chicken. Ind Vet J, 80: 473-474.

Tibaijula B, B Molla, G Hildebrandt and J Kleer, 2003. Occurrence of Salmonella in retail raw chicken products in Ethiopia. Berliner-und-Munchener-Tierarztliche-Wochenschrift, 116: 55-58. 